\title{
ASSOCIATION OF THE ROLE OF PERSONAL VARIABLES AND NONOCCUPATIONAL RISK FACTORS FOR WORK-RELATED CARPAL TUNNEL SYNDROME
}

\author{
Romana Ulbrichtová', Viera Jakušová1, Oto Osina², Jana Zibolenová1, Stanislav Kuka1, Henrieta Hudečková1 \\ ${ }^{1}$ Department of Public Health, Jessenius Faculty of Medicine in Martin, Comenius University in Bratislava, Martin, Slovakia \\ ${ }^{2}$ Clinic of Occupational Medicine and Toxicology, University Hospital in Martin and Jessenius Faculty of Medicine in Martin, Comenius University \\ in Bratislava, Martin, Slovakia
}

\section{SUMMARY}

Objectives: The purpose of this study was to identify personal variables and nonoccupational risk factors for carpal tunnel syndrome and to analyse the strength of association of these factors.

Methods: We performed a case-control study with 162 cases and 300 controls. We studied consecutive patients with an electrophysiologically confirmed diagnosis of symptomatic carpal tunnel syndrome. Univariate analysis was performed in the case group and control comparing them for presence of various risk factors. Multivariate analysis was carried out through logistic regression.

Results: The mean $\mathrm{BMl}$ and age were greater in the case group than in the control. Multivariate analysis showed that $\mathrm{BMI}(\mathrm{OR}=1.05,95 \% \mathrm{Cl}$ $=1.01-1.11)$ and arterial hypertension ( $\mathrm{OR}=4.63,95 \% \mathrm{Cl}=2.88-7.44)$ were the only factors significantly associated with carpal tunnel syndrome. The age, cigarette smoking and alcohol drinking were at the edge of significance.

Conclusions: Carpal tunnel syndrome is the most common peripheral neuropathy and has been related to occupational activities in some but not all studies. Clarifying this relationship has important implications for workers' compensation systems. Based on our findings, BMl and arterial hypertension are considered to be the most significant risk factors of carpal tunnel syndrome in our study.

Key words: carpal tunnel syndrome, risk factors, arterial hypertension, body mass index, age

Address for correspondence: V. Jakušová, Department of Public Health, Jessenius Faculty of Medicine in Martin, Comenius University in Bratislava, Malá Hora 4B, 03601 Martin, Slovakia. E-mail: viera.jakusova@uniba.sk

https://doi.org/10.21101/cejph.a6109

\section{INTRODUCTION}

Carpal tunnel syndrome (CTS) is the most common neuropathy affecting the upper extremities, and the most expensive musculoskeletal disorder in the population. Disease is usually treated with corticoids locally, and surgically or with combined infusion therapy (for example with procain, pentoxyphyllin and magnesium sulphuricum) (1-3). CTS is associated with high health care costs, absence from work, and changes in job duties. The economic costs of CTS can rack up to billions of dollars (4).

People are exposed to the variety of risk factors at work and working environment. These factors may have a negative impact on their health. Health condition of the worker is the result of independent influence of the working, nonoccupational and personal predispositions. This requires a multidisciplinary approach and a comprehensive assessment of the factors at work and the working environment. CTS is one of the most common causes of occupational disabilities. The important factor of CTS as an occupational disease is the impact of work and the working environment, which are largely involved in the development of the disease. On the other hand, the impact of nonoccupational factors should not be neglected. However, personal risk factors leading to CTS are still not well known.

Some studies reported that CTS is associated with certain diseases and /or condition such as diabetes mellitus (DM), higher body mass index (BMI), cardiovascular and thyroid diseases, use of hormonal agents, pregnancy, rheumatoid arthritis, injuries, and work-related factors. In some cases, two or more of these risk factors may coexist, placing the individual factors at a higher risk of developing CTS $(2,5-8)$.

For this reason, the purpose of this study was to examine the association of personal variables and nonoccupational risk factors with the prevalence of work-related CTS.

\section{MATERIALS AND METHODS}

A case-control study was designed with 162 adult patients (78 males, 84 females) from the Clinic of Occupational Medicine and Toxicology, Jessenius Faculty of Medicine in Martin, Comenius University in Bratislava, Slovakia. From January 2018 to Septem- 
ber 2019, we studied consecutive patients with an electrophysiologically confirmed diagnosis of symptomatic CTS including hand numbness, weakness, paresthesia and mostly the nocturnal pain. CTS grade was classified according to the severity of nerve conduction changes into three categories (mild/moderate/severe). Mild CTS was defined by prolonged sensory median latency and normal motor latency $(<4.5 \mathrm{~ms})$. Patients with symptoms suggestive of CTS and abnormal comparative studies were also included in the mild CTS group. Moderate CTS was defined by prolonged sensory median latency plus prolonged motor latency ( $\geq 4.5 \mathrm{~ms}$ ). Severe CTS was defined by severe abnormal sensory findings with or without decreased motor amplitude.

At the same period, 300 subjects (138 males, 162 females) without any known systemic disease or symptoms of CTS were regarded as a control group. Patients in the control group were treated at the Clinic of Occupational Medicine and Toxicology, Slovakia. We obtain a randomly selected control group.

We found out the gender, age, dominant and the affected hand. The age of the patient was defined as the age at the time of the diagnosis of CTS. Gender was determined from the hospital records. Authors considered the possible relationship of CTS with abusus (e.g. alcohol, smoking) both in the case and control group. The item asked patients to identify their status related to smoking on a three-point scale. Current smokers had smoked at least 100 cigarettes in their lifetime and had smoked a cigarette in the past 7 days, former smokers had not smoked a cigarette in the past 7 days but had smoked a cigarette in the past 2 years, and non-smokers. We used a five-response category format of alcohol drinking (daily, once a week or more, once a month or more, less than once a month, never).

Initially, we explored the associations of CTS release with BMI index, DM, and arterial hypertension. Patients passed the anthropometric measurements both in the case and control group. The BMI was used to measure obesity according to classification of the World Health Organization, with weight expressed in kilograms and height in meters $-\mathrm{BMI}=$ weight $(\mathrm{kg}) / \mathrm{height}\left(\mathrm{m}^{2}\right)$. Patients were categorized as not overweight persons if BMI was less than 25 (18.5-25), overweight ones if BMI was 25 or more but less than 30 , obese if BMI was 30 or more but less than 40 , and extremely obese if BMI was 40 or more.

Diseases were categorized according to the International Classification of Diseases (ICD 10). The presence of DM was established by the diagnosis code. We considered arterial hypertension from hospital records by diagnosis code, too.

\section{Statistical Analysis}

Univariate analysis was performed in both groups (case and control) comparing them for presence of various risk factors. Student's t-test was used for comparison between two means for quantitative variables. For the analysis of categorical risk factors for CTS, odds ratio (OR) was calculated, with a $95 \%$ confidence interval $(95 \% \mathrm{CI})$ and evaluated using chi-square test. Multivariate analysis was carried out through logistic regression. Multivariate logistic regression was performed using CTS as the dependent variable to examine the contributions of the following independent variables: age, gender, BMI, cigarette smoking, alcohol drinking, DM, and arterial hypertension. Strength of association was represented with the OR and 95\% CI. Software Epi Info 7 was used for statistical analysis. Results are given as mean and standard deviations (SD). The significance was considered at $\mathrm{p}$ $=0.05$ or less.

\section{RESULTS}

The sample size included 162 cases and 300 controls, structure is shown in Table 1.

There were 162 adult patients, 78 males (48.1\%), 84 (51.9\%) females, with an electrophysiologically confirmed diagnosis of symptomatic CTS, including hand numbness, weakness, paresthesia, and nocturnal pain. CTS was identified in 243 hands (155 right, 88 left) and CTS grade being mild in 109, moderate in 96, and severe in 38 hands.

The mean age of persons in the case group was $52.5(\mathrm{SD}=5.9$, range 27-63) and a median of 52 years, and the mean age of controls was $49.6(\mathrm{SD}=9.4$, range $21-63)$ and a median of 51 years $(\mathrm{p}<0.001)$. BMI in the case group varied from 19.1 to 42.2 with a median of $27.4 \mathrm{~kg} / \mathrm{m}^{2}$, and BMI in the control group varied from 17.8 to 39.2 with a median of $27.4 \mathrm{~kg} / \mathrm{m}^{2}$. The mean BMI was greater in the case $($ mean $=28.8, \mathrm{SD}=4.6)$ than in the control group $($ mean $=26.8, \mathrm{SD}=4.6)(\mathrm{p}<0.001)($ Table 2$)$.

Of 162 patients, 81 (50\%) suffered from the bilateral CTS, 74 (45.7\%) of them had CTS only on the right side, and 7 (4.3\%) on the left side.

Of the patients with CTS, 79\% have mentioned their arterial hypertension and $22.8 \% \mathrm{DM}$.

The results of univariate analysis examining the relationship of qualitative variables to CTS are shown in Table 2. Cigarette smoking $(\mathrm{OR}=2.11,95 \% \mathrm{CI}=1.42-3.14)$, alcohol drinking $(\mathrm{OR}$ $=1.6,95 \% \mathrm{CI}=1.03-2.49)$, arterial hypertension $(\mathrm{OR}=6.14,95 \%$ $\mathrm{CI}=3.94-9.58)$, and $\mathrm{DM}(\mathrm{OR}=3.26,95 \% \mathrm{CI}=1.88-5.64)$ were significant predictors of CTS (Table 3 ).

When we performed multivariate logistic regression analysis, BMI $(\mathrm{OR}=1.05,95 \% \mathrm{CI}=1.01-1.11)$ and arterial hypertension $(\mathrm{OR}=4.63,95 \% \mathrm{CI}=2.88-7.44)$ were the only factors significantly associated with CTS. Other factors did not approach conventional levels of statistical significance. However, the age, cigarette smoking and alcohol drinking were at the border of significance (Table 4).

Table 1. Structure of cases and controls

\begin{tabular}{|l|c|c|}
\hline Variable & Cases $(\mathrm{n}=162)$ & Controls $(\mathrm{n}=\mathbf{3 0 0})$ \\
\hline Age (years), mean (SD) & $52.5(5.9)$ & $49.6(9.4)$ \\
\hline Gender \\
\hline Male n (\%) & $78(48.1)$ & $138(46)$ \\
\hline Female $\mathrm{n}(\%)$ & $84(51.9)$ & $162(54)$ \\
\hline
\end{tabular}

Table 2. Comparison of quantitative variables in case and control group (Student's t-test)

\begin{tabular}{|l|c|c|c|}
\hline Variable & Case & Control & p-value \\
\hline Age $($ years), mean (SD) & $52.5(5.9)$ & $49.6(9.4)$ & $<0.001$ \\
\hline BMI $\left(\mathrm{kg} / \mathrm{m}^{2}\right)$, mean (SD) & $28.8(4.6)$ & $26.8(4.6)$ & $<0.001$ \\
\hline
\end{tabular}


Table 3. Univariate analysis of potential risk factors (qualitative variables) in case and control group

\begin{tabular}{|c|c|c|c|c|}
\hline Variable & $\begin{array}{c}\text { Cases }(n=162) \\
n(\%)\end{array}$ & $\begin{array}{c}\text { Controls }(n=300) \\
n(\%)\end{array}$ & OR $(95 \% \mathrm{Cl})$ & $\mathrm{p}$-value \\
\hline \multicolumn{5}{|l|}{ Gender } \\
\hline Male & $78(48.1)$ & $138(46)$ & \multirow{2}{*}{$0.92(0.63-1.35)$} & \multirow{2}{*}{0.59} \\
\hline Female & $84(51.9)$ & $162(54)$ & & \\
\hline Cigarette smoking & $77(47.5)$ & $90(30)$ & $2.11(1.42-3.14)$ & $<0.001$ \\
\hline Alcohol drinking & $126(77.8)$ & $206(68.7)$ & $1.6(1.03-2.49)$ & 0.038 \\
\hline Arterial hypertension & $128(79)$ & $114(38)$ & $6.14(3.94-9.58)$ & $<0.001$ \\
\hline Diabetes mellitus & $37(22.8)$ & $25(8.3)$ & $3.26(1.88-5.64)$ & $<0.001$ \\
\hline
\end{tabular}

$95 \% \mathrm{Cl}-95 \%$ confidence interval; OR - odds ratio

Table 4. Multivariate logistic regression analysis

\begin{tabular}{|l|c|c|}
\hline Variable & OR $(95 \% \mathrm{Cl})$ & p-value \\
\hline Age & $1.03(1.0-1.07)$ & 0.051 \\
\hline Gender (male/female) & $1.31(0.83-2.06)$ & 0.249 \\
\hline BMl & $1.05(1.01-1.11)$ & 0.031 \\
\hline Cigarette smoking & $1.51(0.94-2.42)$ & 0.088 \\
\hline Alcohol drinking & $1.58(0.95-2.64)$ & 0.076 \\
\hline Arterial hypertension & $4.63(2.88-7.44)$ & $<0.001$ \\
\hline Diabetes mellitus & $1.36(0.733-2.51)$ & 0.330 \\
\hline
\end{tabular}

$95 \% \mathrm{Cl}-95 \%$ confidence interval, OR - odds ratio

\section{DISCUSSION}

CTS is the most common peripheral neuropathy related to occupational activities in some but not all studies. Clarifying this relationship has important implications for workers' compensation systems around the world. The findings of our study confirm that age, BMI, arterial hypertension, DM, cigarette smoking, and alcohol drinking are the risk factors for CTS, as they have been described by other authors $(2,6,9-12)$.

Maghsoudipour et al. (13) suggested that male gender is a possible risk factor for CTS. Other studies suggested female gender as a possible risk factor for CTS $(2,6,9)$. Buchancova (14) stated that the differences between men and women may vary according to the character of the work performed during the life and also the menopause of women can play a significant role in the development of CTS. On the other hand, female reproductive hormonal profiles over the course of the menstrual cycle have significant influences on thermoregulatory and volume regulatory physiology. Mainly, the luteal phase is characterized by high concentrations of both estrogen and progesterone in circulation. These hormones have been associated with variation in body fluid regulation and may have independent impacts on hydration and body fluid balance (15). Hormonal fluctuations, fluid accumulation with tendency to oedemas and nerve hypersensitivity are factors that predispose women to the development of CTS symptoms (16).

Most studies reported that the risk period for CTS increased with increasing age (17-19). According to our results the gender reached the borderline level of statistical significance $(p=0.051)$ with OR greater than 1 . The mean age was greater in case than in control group $(\mathrm{p}<0.001)$.
The estimated prevalence rates for CTS have been $1-5 \%$ in the general population (20). The study of Maghsoudipour et al. (13) showed that $11.9 \%$ of industrial workers with manual work were diagnosed with CTS. In the following long-term study lasting 11 years, authors reported about $13 \%$ of CTS among industrial workers (21).

Pourmemari and Shiri (8) via meta-analysis have suggested DM is a risk factor for CTS. The magnitude of the association is modest, and does not differ between type 1 and type 2 DM. Pandey et al. (22) found that the hand disorders were present in two third of the patients with type $2 \mathrm{DM}$, and the prevalence of hand disorder increases with duration of DM. In our study, the results of univariate regression analysis established $\mathrm{DM}(\mathrm{OR}=3.26,95 \%$ $\mathrm{CI}=1.88-5.64)(\mathrm{p}<0.001)$ as one predictor of CTS. On the other hand, our results from multivariate analysis did not reach the conventional level of statistical significance. The observed association between DM and CTS may partly attribute to confounding factors. The adverse effects of DM on peripheral nerves have been studied extensively, but the mechanism how DM may increase the risk of CTS is still not clear. Median nerve neuropathy is a complication of DM. A reduction in myelinated nerve fibre and endoneurial capillary densities was found in patients with DM who were not exposed to nerve compression. A low axonal density may lead to median nerve neuropathy (23). Moreover, in patients with DM the advanced glycation end-products can increase a production of circulating inflammatory cytokines and vascular endothelial growth factor, which in turn may cause impaired microvascular circulation and result in demyelination and axonal degeneration of the median nerve $(24,25)$.

In the case of BMI, its relationship to CTS has been well known. Our findings were consistent with the results of most published studies. The association between obesity (BMI $\geq 30$ ) and CTS can be explained either by the accumulation of fat tissue inside the carpal tunnel or by swelling caused by an increase of hydrostatic pressure within the canal, exerting a compressive effect on the median nerve. However, in agreement with the findings of Werner et al. (9), obesity was shown to be a stronger risk. Our study confirmed that BMI was statistically significant $(\mathrm{p}=0.031), \mathrm{OR}=1.05$, like it was reported by other authors in their meta-analysis (26), where each unit rise in BMI had increased the risk of CTS by $7.4 \%$ (adjusted OR=1.074). Also some studies have reported that obesity $(\mathrm{BMI} \geq 30)$ is associated with an increased risk of CTS $(27,28)$. On the other hand, CTS is often accompanied by pain, which can cause limited mobility or sick 
leaves. These factors can be considered as one of the causes of overweight to obesity in CTS patients.

The meta-analysis showed an association between current smoking and CTS (11). However, the case-control and cohort studies showed no association between current smoking and CTS (11). In general, there is a relationship between smoking and arterial hypertension as well as between the cigarette smoking and drinking of alcohol.

However, the results of the association between arterial hypertension and CTS cannot be considered unambiguous. There are few studies that clearly confirm this relationship. In this case, other comprehensive studies with larger sample should aim to investigate the biological plausibility of the association between arterial hypertension and CTS. We are in line with the results of author who reported that persons suffering from arterial hypertension were at increased risk of CTS (29). Our results of univariate $(\mathrm{OR}=6.14,95 \% \mathrm{CI}=3.94-9.58, \mathrm{p}<0.001)$ and multivariate regression analyses $(\mathrm{OR}=4.63,95 \% \mathrm{CI}=2.88-7.44, \mathrm{p}<0.001)$ have proved the arterial hypertension as significant risk factor for CTS. CTS may result from any factor leading to deformity in the size of the carpal tunnel or swelling of its contents. One of the plausible reasons is that the median nerve may be injured by direct mechanical pressure, and/or its function may be impaired by venous congestion, oedema and arterial insufficiency (30). Another explanation is that some drugs, including statins and fibrates, widely used in treatment of the arterial hypertension are supposed to cause a peripheral neuropathy. Treatment indications with statins are hypercholesterolemia and prevention of cardiovascular diseases that can lead to the reduction of morbidity and mortality (31). According to Corrao et al. (31) the study estimates that users of lipid lowering drugs are at 1.3-fold increased risk for the development of peripheral neuropathy. Further evidence that treatment with statins is associated with increased risk of peripheral neuropathy was also provided. With regard to the findings of other studies, we can hypothesize that statin consumption may cause changes in the peripheral nerves and may result in axonal damage $(31,32)$.

\section{CONCLUSIONS}

Although CTS causes considerable disability for patients, many of risk factors are still poorly defined. CTS is multifactorial disease, therefore, one factor cannot be considered alone as the cause of the disease. The multifactorial aetiology of CTS is poorly understood, and there are several risk factors commonly believed to be associated with increased risk for this ailment. In our study arterial hypertension and BMI were possible independent risk factors for development of CTS. However, other comprehensive studies with larger sample should aim to investigate these and other risk factors in order to create a better understanding of the role of these factors in aetiology of CTS. Our study requires further research and expansion of the cases and controls in order to further determine the relationship between the monitored variables.

\section{Conflicts of Interests}

None declared

\section{Funding}

This work was supported by the Slovak Research and Development Agency under the contract no. APVV-19-0214.

\section{Adherence to Ethical Standards}

The study protocol was approved by the Ethics Committee of the Jessenius Faculty of Medicine in Martin, Comenius University in Bratislava, Slovakia, reference number EK 138/2018, and was performed in accordance with the guidelines proposed in the Declaration of Helsinki (2000) of the World Medical Association.

\section{REFERENCES}

1. Evanoff B, Gardner BT, Strickland JR, Buckner-Petty S, Franzblau A, Dale AM. Long term symptomatic, functional, and work outcomes of carpal tunnel syndrome among construction workers. Am J Ind Med. 2016;59(5):357-68.

2. Kouyoumdjian JA, Zanetta DM, Morita MPA. Evaluation of age, body mass index, and wrist index as risk factors for carpal tunnel syndrome severity. Muscle Nerve. 2002;25(1):93-7.

3. Fialova J, Bartousek J, Nakladalova M. Alternative treatment of the carpal tunnel syndrome. Cent Eur J Public Health. 1999;7(4):168-71.

4. Fernández-De-Las-Peñas C, Ortega-Santiago R, Díaz HF, Salom-Moreno J, Cleland JA, Pareja JA, et al. Cost-Effectiveness evaluation of manual physical therapy versus surgery for carpal tunnel syndrome: evidence from a randomized clinical trial. J Orthop Sports Phys Ther. 2019;49(2):55-63.

5. Stetson DS, Albers JW, Silverstein BA, Wolfe RA. Effects of age, sex, and anthropometric factors on nerve conduction measures. Muscle Nerve. 1992;15(10):1095-104.

6. Becker J, Nora DB, Gomes I, Stringari FF, Seitensus R, Panosso JS, et al. An evaluation of gender, obesity, age and diabetes mellitus as risk factors for carpal tunnel syndrome. Clin Neurophysiol. 2002;113(9):1429-34.

7. Burger MC, Abrahams S, Collins M. Non-occupational risk factors for carpal tunnel syndrome: a review. Womens Health Bull. 2016;3(2):e34820. doi: 10.17795/WHB-34820.

8. Pourmemari MH, Shiri R. Diabetes as a risk factor for carpal tunnel syndrome: a systematic review and meta-analysis. Diabet Med. 2016;33(1):10-6.

9. Werner RA, Albers JW, Franzblau A, Armstrong TJ. The relationship between body mass index and the diagnosis of carpal tunnel syndrome. Muscle Nerve. 1994;17(6):632-6.

10. Stallings SP, Kasdan ML, Soergel TM, Corwin HM. A case-control study of obesity as a risk factor for carpal tunnel syndrome in a population of 600 patients presenting for independent medical examination. J Hand Surg. 1997;22(2):211-5.

11. Pourmemari MH, Viikari-Juntura E, Shiri R. Smoking and carpal tunnel syndrome: a meta-analysis. Muscle Nerve. 2014;49(3):345-50.

12. Lam N, Thurston A. Association of obesity, gender, age and occupation with carpal tunnel syndrome. Aust N Z J Surg. 1998;68(3):190-3.

13. Maghsoudipour M, Moghimi S, Dehghaan F, Rahimpanah A. Association of occupational and non-occupational risk factors with the prevalence of work related carpal tunnel syndrome. J Occup Rehabil. 2008;18(2):152-6.

14. Buchancova J. Occurrence, etiopathogenesis and clinic of carpal tunnel syndrome from the perspective of occupational medicine. Medicínsky Monitor. 2000;2000(6):12-6. (In Slovak.)

15. Sherman BM, Korenman SG. Hormonal characteristics of the human menstrual cycle throughout reproductive life. J Clin Invest. 1975;55(4):699706.

16. Dieck GS, Kelsey JL. An epidemiologic study of the carpal tunnel syndrome in an adult female population. Prev Med. 1985;14(1):63-9.

17. Wolf JM, Mountcastle S, Owens BD. Incidence of carpal tunnel syndrome in the US military population. Hand (N Y). 2009;4(3):289-93.

18. Violante FS, Armstrong TJ, Fiorentini C, Graziosi F, Risi A, Venturi S, et al. Carpal tunnel syndrome and manual work: a longitudinal study. J Occup Environ Med. 2007;49(11):1189-96.

19. Harris-Adamson C, Eisen EA, Dale AM, Evanoff B, Hegmann KT, Thiese MS, et al. Personal and workplace psychosocial risk factors for carpal tunnel syndrome: a pooled study cohort. Occup Environ Med. 2013;70(8):529-37. 
20. Atroshi I, Gummesson C, Johnsson R, Ornstein E, Ranstam J, Rosen I. Prevalence of carpal tunnel syndrome in a general population. JAMA. 1999;282(2):153-8.

21. Nathan PA, Meadows KD, Istvan JA. Predictors of carpal tunnel syndrome: an 11-year study of industrial workers. J Hand Surg Am. 2002;27(4):644-51.

22. Pandey A, Usman K, Reddy H, Gutch M, Jain N, Qidwai SA. Prevalence of hand disorders in type 2 diabetes mellitus and its correlation with microvascular complications. Ann Med Health Sci Res. 2013;3(3):349-54.

23. Dahlin LB, Sanden H, Dahlin E, Zimmerman M, Thomsen N, Bjorkman A. Low myelinated nerve-fibre density may lead to symptoms associated with nerve entrapment in vibration-induced neuropathy. J Occup Med Toxicol. 2014;9(1):7. doi: 10.1186/1745-6673-9-7.

24. Goldin A, Beckman JA, Schmidt AM, Creager MA. Advanced glycation end products: sparking the development of diabetic vascular injury. Circulation. 2006;114(6):597-605.

25. Mojaddidi MA, Ahmed MS, Ali R, Jeziorska M, Al-Sunni A, Thomsen NOB, et al. Molecular and pathological studies in the posterior interosseous nerve of diabetic and non-diabetic patients with carpal tunnel syndrome. Diabetologia. 2014;57(8):1711-9.

26. Shiri R, Pourmemari MH, Falah-Hassani K, Viikari-Juntura E. The effect of excess body mass on the risk of carpal tunnel syndrome: a meta-analysis of 58 studies. Obes Rev. 2015;16(12):1094-104.
27. Petit A, Ha C, Bodin J, Rigouin P, Descatha A, Brunet R, et al. Risk factors for carpal tunnel syndrome related to the work organization: a prospective surveillance study in a large working population. Appl Ergon. 2015;47:1-10

28. Burt S, Deddens JA, Crombie K, Jin Y, Wurzelbacher S, Ramsey J. A prospective study of carpal tunnel syndrome: workplace and individual risk factors. Occup Environ Med. 2013;70(8):568-74.

29. Tseng C-H, Liao C-C, Kuo C-M, Sung F-C, Hsieh DPH, Tsai C-H. Medical and non-medical correlates of carpal tunnel syndrome in a Taiwan cohort of one million. Eur J Neurol. 2012;19(1):91-7.

30. Dorwart BB. Carpal tunnel syndrome, a review. Semin Arthritis Rheum. 1984;14(2):134-40.

31. Corrao G, Zambon A, Bertù L, Botteri E, Leoni O, Contiero P. Lipid lowering drugs prescription and the risk of peripheral neuropathy: an exploratory case-control study using automated databases. J Epidemiol Community Health. 2004;58(12):1047-51.

32. Emad M, Arjmand H, Farpour HR, Kardeh B. Lipid-lowering drugs (statins) and peripheral neuropathy. Electron Physician. 2018;10(3):6527-33.

Received January 23, 2020 Accepted in revised form November 10, 2020 